\title{
A internalização da Previdência Social Rural na autonomia e no consumo dos idosos: um estudo de caso
}

\author{
Rossandra Oliveira Maciel de Bitencourt ${ }^{\circ}$ \\ Fabiano Abranches Silva Dalto*
}

\begin{abstract}
Resumo: O presente trabalho tem por objetivo analisar a internalização da Previdência Social Rural (PSR) na autonomia e no consumo dos idosos em municípios pertencentes à região da AMREC - Associação dos Municípios da Região Carbonífera (localizada no sul do estado de Santa Catarina). A metodologia utilizada foi um estudo de caso, em que foram entrevistados trinta aposentados rurais e dois representantes sindicais locais. A abordagem de análise foi qualitativa. Dentre os resultados identificou-se que na perspectiva dos idosos, a PSR possui um significado singular. Para alguns, ela representa um complemento na renda, permitindo mudanças e melhorias no padrão de vida. Para outros, ela é a única fonte de renda responsável pela manutenção da sobrevivência. Em suma, esta pesquisa mostrou que a PSR internaliza-se ao garantir ao idoso, sobretudo, autonomia e independência, criando assim as condições para que a velhice seja um momento propício à elaboração a realização de projetos de vida.
\end{abstract}

Palavras-Chave: Previdência Social Rural, Idoso, Consumo, Autonomia.

Abstract: This work was developed in order to analyze the social changes on autonomy and consumption of rural seniors arising from the pension benefits provisioning in rural communities in municipalities of AMREC - Association of Municipalities of Carboniferous Area. The methodology used was a case study in which were interviewed thirty rural retirees and two local union representatives. The analysis approach was qualitative. From the perspective of the elderly, the benefits have reinforcing multiple social effects. For some, it is a complement in income, allowing changes and improvements in living standards. For others, it is the only source of income responsible for maintaining survival. In short, we have found that the pension benefits have ensured the elderly autonomy and independence, thus creating the conditions for them to realize ongoing life projects.

Keywords: Rural Social Security, Elderly, Consumption, Autonomy

\section{Introdução}

A Previdência Social Rural (PSR) no Brasil é uma política pública fundamental por não impor condicionalidades ao acesso com relação à renda ou ao estrato social. Por ser uma das principais políticas públicas voltadas ao meio rural ela ganhou notoriedade ao promover resultados socioeconômicos positivos, não somente para o campo, mas para a economia dos pequenos municípios rurais em todo o país.

Segundo Delgado e Cardoso Jr. (1999), foi com a redemocratização do país e com a promulgação da Constituição Federal de 1988 que a PSR começou a se consolidar no Brasil. Contudo, conforme destacam estes autores, as mudanças mais sólidas da PSR foram estabelecidas de fato somente em 1992, com a aplicação das leis complementares $N^{0} 8.212$ e No8.213 de 24 de junho de 1991 que instituíram o Plano de Custeio e o Plano de Benefícios, promovendo a universalização do programa previdenciário rural brasileiro. Estas se traduziram na aplicação das seguintes regras: equiparação

\footnotetext{
- Doutoranda em Políticas Públicas pela Universidade Federal do Paraná.

* Doutor pela Universidade de Hertfordshire (2007), professor do departamento de Economia e do Programa de Pós-Graduação em Políticas Públicas da Universidade Federal do Paraná.
} 
do acesso ao benefício para homens e mulheres; redução da idade mínima para aposentadoria (60 anos para os homens e 55 para mulheres); e o piso de um salário mínimo para aposentadorias e pensões (superando o meio salário mínimo vigente anteriormente).

Com a efetivação da PSR na década de 1990, a cobertura do sistema previdenciário sobre os residentes rurais aumentou substancialmente. Os estudos de Schwarzer e Querino (2002), Bezerra (2006), Sugamosto (2007), Caldas (2008) revelam uma contribuição significativa da PSR para diversas regiões, áreas e níveis de agregação: i) na composição da renda das famílias, ao possibilitar a redução da pobreza no meio rural por meio da redistribuição de renda; ii) na aquisição de medicamentos e no acesso aos serviços privados de saúde; iii) no sustento de filhos e netos desempregados ou subempregados; iv) ao permitir melhorias nas moradias; v) ao ser empregada como seguro agrícola nas pequenas propriedades; vi) e ao se traduzir, em muitos casos, em uma das principais fontes de receitas para os municípios.

Contudo, embora a PSR apresente um amplo impacto no que tange à realidade rural brasileira, ela é ainda pouco debatida na academia, tendo em vista que a ruralidade foi, durante muito tempo, sinônimo de atraso. ${ }^{1}$ A invisibilidade da PSR no âmbito acadêmico também está atrelada ao baixo investimento em políticas públicas no meio rural em comparação ao meio urbano. No sul do Estado de Santa Catarina, mais precisamente no meio rural da Associação dos Municípios da Região Carbonífera (AMREC), não havia até então estudos sobre os efeitos da PSR na vida dos idosos. Frente a este cenário, desenvolveu-se a presente pesquisa com o objetivo de analisar a internalização da Previdência Social Rural (PSR) na autonomia e no consumo dos idosos em municípios pertencentes à referida região.

Neste estudo o idoso é visto como uma categoria central para o debate. Trabalha-se com a perspectiva de geração a partir de Motta (2010) e Barros (2006), autoras que buscam ir além do etarismo assumindo assim esta categoria em um contexto de pluralidade, marcado por grupos heterogêneos compostos por diferentes trajetórias de vida. Como suporte teórico, toma-se do referencial da sociologia econômica os conceitos de internalização, hábito, habitus e valores morais.

Por fim, é preciso salientar que o objetivo desta pesquisa perpassa um debate central acerca da universalização da PSR no âmbito do Estado como provedor de direitos sociais. Para tanto, a partir de Skocpol (1985), Pitelis (1994); Screpanti (2001), Hodgson (2006) e Draibe (1985) assume-se nesta pesquisa o Estado como uma estrutura institucional que, em constante transformação, é capaz de influenciar de diferentes formas a sociedade bem como a vida dos indivíduos.

O presente trabalho está dividido em cinco partes: após esta breve introdução, adentra-se aos aspectos metodológicos, em seguida discute-se

\footnotetext{
${ }^{1}$ Uma busca por meio das palavras-chave Previdência Social Rural e Social Rural Security, realizada nas principais bases de periódicos científicos - Dialnet, Scielo, Redalyc, DOAJ, ICAP, Google Acadêmico, Banco de Periódicos CAPES, e Web of Science - revelou a publicação de 23 artigos cuja abordagem centra-se nos impactos da PSR na vida dos idosos do campo ou nos municípios rurais. Esta mesma pesquisa também foi realizada no Banco de Teses da CAPES, e verificou-se que no período de 1987-2013 foram desenvolvidos apenas 21 estudos que abordassem a contribuição da PSR na vida do idoso do campo.
} 
alguns conceitos centrais pautados no referencial analítico institucional; na sequência estão os resultados da pesquisa; e por fim, as considerações finais acerca do que foi encontrado.

\section{Aspectos metodológicos}

No tocante à metodologia, realizou-se um estudo de caso, cuja amostra foi construída por acessibilidade. Foram entrevistados trinta aposentados rurais: dezessete no município de Forquilhinha, em meio às tardes de confraternizações do Clube dos Idosos; cinco em domicílios no município de Nova Veneza; e, por fim, oito no município de Treviso, em uma tarde de confraternização do Clube de Mães. Foram realizadas também duas entrevistas com representantes locais, contemplando o presidente do Sindicato dos Trabalhadores Rurais de Forquilhinha, e o presidente do Sindicato dos Trabalhadores Rurais de Içara.

A fim de analisar a internalização da PSR na autonomia dos idosos, buscou-se trabalhar com três eixos principais. $O$ primeiro se refere ao consumo, que neste caso corresponde à aquisição de todos os tipos de bens desde os mais básicos necessários à subsistência, até os bens materiais responsáveis por proporcionar maior conforto e qualidade de vida. O segundo corresponde à autonomia proporcionada pela PSR à mulher frente ao cônjuge. E o terceiro meio de analisar a autonomia do idoso foi frente ao contexto familiar, verificando se os idosos fornecem ajuda financeira a filhos e netos.

Para delimitação da amostra, utilizou-se o fechamento por saturação que, de acordo com Gil (1999), consiste na suspensão de inclusão de novos participantes quando as informações obtidas tornam-se repetitivas. O instrumento de coleta de dados se deu por meio de entrevistas com roteiro semiestruturado. A abordagem de análise foi qualitativa, em que se obteve dados descritivos, por meio do contato direto do pesquisador com a situação objeto de estudo.

A seguir adentra-se ao referencial analítico institucional, cujo aparato teórico dará suporte à análise empírica da pesquisa.

\section{Referencial Analítico Institucional}

Pretende-se trabalhar aqui alguns conceitos a fim de entender como a Previdência Social Rural (PSR) é internalizada nos hábitos dos aposentados. Para tanto, são desenvolvidas a seguir as principais categorias teóricas que darão suporte à análise empírica deste estudo: internalização, hábito, habitus e valores morais.

\subsection{Hábito e o efeito reconstitutivo descendente}

Embora não seja possível unificar o conceito de instituição, segundo Hodgson (2006), faz-se fundamental entender algumas concepções acerca do termo, visto que uma análise empírica demanda conhecimento sobre como elas funcionam ou se organizam. Hodgson considera que as instituições são as estruturas de maior relevância da vida social. Elas consistem em sistemas duráveis de regras sociais incorporadas pelas pessoas, que prevalecem sobre as interações sociais, estruturando-as e criando expectativas estáveis de 
comportamento, pois elas estão atreladas aos pensamentos e atividades dos indivíduos.

Nessa discussão, o hábito - desencadeado por um estímulo em um contexto específico - emerge como uma disposição a se engajar em determinados comportamentos ou pensamentos. $O$ hábito não é 0 comportamento em si, mas a inclinação em responder de alguma forma a determinados estímulos. Os estímulos por sua vez, promovidos por políticas públicas atuam através dos hábitos até alcançarem certos resultados. No caso, a presente definição remete pensar a instituição da PSR como uma política que, ao ser incorporada à vida dos idosos, por se tornar um elemento de seus hábitos de pensamento, pode desencadear novos comportamentos ou reforçar comportamentos já existentes, a exemplo do hábito de consumir.

As instituições não se restringem apenas aos pensamentos e ações coletivas. Hodgson (2003) alega que, por serem estruturas sociais, elas são capazes de exercer uma pressão persuasiva sobre os indivíduos, denominada efeito reconstitutivo descendente. Esse efeito ocorre através da característica mais oculta e penetrante das instituições: sua capacidade de criar e moldar os hábitos de pensamento e, então, a ação individual. Nesse âmbito, o efeito reconstitutivo descendente começa por meio da reformulação de antigos hábitos $\mathrm{e}$, na medida em que o novo se estabelece, torna-se então uma base para a criação de novos comportamentos (HODGSON, 2003).

No contexto descrito pode-se entender a institucionalização da PSR como um mecanismo capaz de moldar as propensões e disposições habituais dos idosos. Ao se tornarem beneficiados, a estabilidade proporcionada pela PSR pode possibilitar a criação de novas preferências, aspirações, desejos, valores e até mesmo novos comportamentos que seriam impossíveis numa situação de renda incerta ou variável. A fim de fomentar este debate, a seguir apresenta-se o conceito de habitus desenvolvido por Bourdieu.

\subsection{Habitus e o estilo de vida}

Bourdieu (2008) desenvolve o conceito de habitus atrelado ao estilo de vida, como sendo capaz de realizar uma aplicação universal, ao fazer com que o conjunto de práticas de um agente ocorra de forma sistemática por meio da aprendizagem. Segundo o autor, esta ocorre a partir da aplicação de esquemas idênticos e constitutivos, inseridos em determinados estilos de vida. $E$ estes esquemas, geradores do habitus, aplicam-se por simples transferência em meio à aprendizagem.

Assim, para construir o espaço dos estilos de vida, nos quais se define uma série de coisas, a exemplo do consumo, Bourdieu (2008) atenta para a necessidade de ter-se clara a fórmula geradora do habitus. Essa se faz responsável por retraduzir as necessidades e as facilidades de suas condições de existência homogêneas. O autor acrescenta à discussão que o gosto propensão e aptidão para a apropriação material de determinados objetos - é uma fórmula geradora que se encontra na origem do estilo de vida.

Por fim, cabe destacar que Bourdieu e Hodgson, ao proporem os conceitos de hábito e habitus não estão atuando diretamente sobre as decisões individuais, mas sim sobre as disposições habituais, na quais as instituições ganham centralidade sem, contudo, reduzir as peculiaridades individuais. Assim, pode-se dizer que ambos os autores superam o dilema entre o 
individualismo metodológico e o coletivismo metodológico que tanto marca os estudos em ciências sociais.

A seguir, adentra-se à discussão sobre a internalização das instituições na vida dos indivíduos.

\subsection{Internalização das instituições e valores morais}

Preocupada em relacionar as instituições com a cognição humana, Douglas (1998) parte do princípio de que as instituições estão na base do pensamento dos indivíduos, desempenhando o "molde social da cognição" em meio a um "agrupamento social legitimado". Tal como Bourdieu (2008), a autora destaca que os indivíduos não tomam decisões sozinhos e argumenta que o pensamento institucional está em suas mentes, influenciando-os constantemente.

A seguir, a Figura 1 sintetiza os principais conceitos da sociologia econômica vistos até aqui:

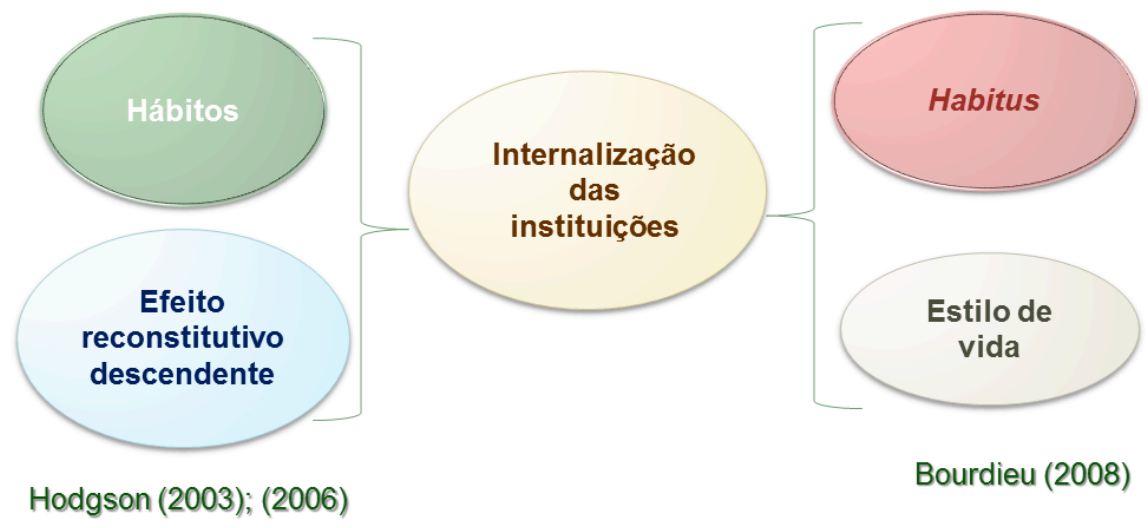

FIGURA 1 - REFERENCIAL DA SOCIOLOGIA ECONÔMICA

Fonte: Elaboração própria

O termo internalização faz referência mais precisamente à mudança institucional promovida pelas instituições na vida dos indivíduos. A Figura 1 demonstra que tal processo se dá através da reconstituição dos hábitos, que leva a formação de novos pensamentos, disposições, e aí então, novos comportamentos. A internalização por sua vez se dá no contexto no qual o indivíduo está inserido, o que pressupõe que as necessidades, preferências e propensões são construídas em meio à história, ao habitus e ao estilo de vida de cada um.

Também é central para esta análise o papel desempenhado pelas instituições na produção de valores morais. Conforme Douglas (1998), eles estabilizam o fluxo da vida social, criando realidades que se aplicam aos indivíduos. Segundo a autora, as opiniões morais são formadas em meio às instituições sociais, de modo que os próprios julgamentos são igualmente criados através de instituições.

Após a abordagem das categorias centrais que darão suporte a análise empírica, a seguir estão os resultados identificados na presente pesquisa.

\section{Universo analítico: Associação dos Municípios da Região Carbonífera}


A Associação dos Municípios da Região Carbonífera, conforme demonstra a Figura1, é composta por doze municípios: Balneário Rincão, Cocal do Sul, Criciúma, Forquilhinha, Içara, Lauro Muller, Morro da Fumaça, Nova Veneza, Orleans, Siderópolis, Treviso e Urussanga. Entretanto, conforme já destacado, a amostra foi definida por acessibilidade, de modo que a presente pesquisa contempla aposentados rurais residentes nos municípios de Forquilhinha, Nova Veneza e Treviso.
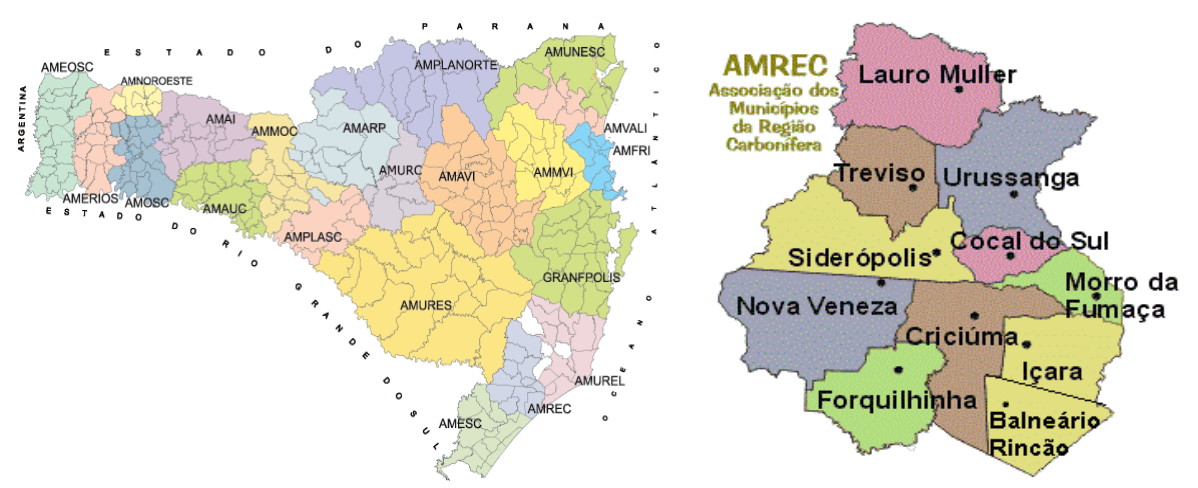

FIGURA 1 - MUNICÍPIOS PERTENCENTES À REGIÃO DA AMREC - SC Fonte: AMREC (2014)

De acordo com os dados do Censo do Instituto Brasileiro de Geografia e Estatística (IBGE), a AMREC teve um crescimento populacional de $12 \%$ entre 2000 e 2010, apresentando no último Censo 390.791 habitantes. No entanto, com relação à população rural, verificou-se, ao contrário, uma redução populacional de $33 \%$ para o mesmo período, de modo que residiam no meio rural da região o total de 42.857 pessoas. Já a população rural com mais de 60 anos teve uma redução de apenas $0,75 \%$ nesse período, um percentual muito inferior à redução da população total rural, de modo que segundo o último Censo havia um total de 6.407 potenciais aposentados rurais (mulheres acima de 55 anos de idade, e homens acima de 60 anos) residindo no meio rural da AMREC.

Esta dinâmica populacional determina, portanto, os fenômenos do êxodo rural e do envelhecimento do campo na região, o que nos leva a inferir que boa parte dos idosos rurais esteja permanecendo no campo através da renda da PSR. A seguir, são apresentados os resultados deste estudo a fim de verificar como a PSR internaliza-se nos hábitos de consumo e na autonomia dos aposentados rurais.

\subsection{PSR, consumo e autonomia dos idosos}

Conforme dito previamente nos aspectos metodológicos, dividiu-se a análise empírica acerca da internalização da PSR na autonomia dos idosos em três eixos principais: consumo; autonomia proporcionada pela PSR à mulher frente ao cônjuge; e autonomia dos idosos frente ao contexto familiar. A seguir, a Tabela $1^{2}$ apresenta de forma sucinta estas informações.

\footnotetext{
${ }^{2}$ Para manter o sigilo referente à identidade dos idosos, as informações foram organizadas de acordo com a ordem das entrevistas.
} 


\section{TABELA 1 - PREVIDÊNCIA SOCIAL RURAL, CONSUMO E AUTONOMIA DOS} IDOSOS

\begin{tabular}{|c|c|c|c|c|c|c|}
\hline ENTREVISTADO & MUNICÍPIO & SEXO & IDADE & $\begin{array}{l}\text { DEPENDE } \\
\text { APENAS DA } \\
\text { PSR }\end{array}$ & $\begin{array}{l}\text { ADQUIRIU BENS } \\
\text { MATERIAIS } \\
\text { APÓS SE } \\
\text { APOSENTAR }\end{array}$ & $\begin{array}{l}\text { AJUDA } \\
\text { FINANCEIRA } \\
\text { A FILHOS OU } \\
\text { NETOS }\end{array}$ \\
\hline 1 & Forquilhinha & $M$ & 65 & Não & Não & Sim \\
\hline 2 & Forquilhinha & $\mathrm{F}$ & 72 & Sim & Não & Sim \\
\hline 3 & Forquilhinha & $\mathrm{F}$ & 67 & Não & Não & Sim \\
\hline 4 & Forquilhinha & $M$ & 70 & Não & Não & Sim \\
\hline 5 & Forquilhinha & $\mathrm{M}$ & 64 & Não & Sim & Não \\
\hline 6 & Forquilhinha & $M$ & 76 & Sim & Sim & Não \\
\hline 7 & Forquilhinha & $\mathrm{F}$ & 64 & Não & Sim & Não \\
\hline 8 & Forquilhinha & $\mathrm{F}$ & 69 & Sim & - & Não \\
\hline 9 & Forquilhinha & $\mathrm{M}$ & 68 & Não & Sim & Não \\
\hline 10 & Forquilhinha & $\mathrm{F}$ & 75 & Não & Sim & Sim \\
\hline 11 & Forquilhinha & $\mathrm{F}$ & 76 & Sim & Sim & Não \\
\hline 12 & Forquilhinha & $M$ & 68 & Sim & Sim & Não \\
\hline 13 & Forquilhinha & $\mathrm{F}$ & 72 & Não & Sim & Não \\
\hline 14 & Nova Veneza & $\mathrm{F}$ & 77 & Não & Sim & Sim \\
\hline 15 & Nova Veneza & $\mathrm{F}$ & 72 & Não & Sim & Sim \\
\hline 16 & Nova Veneza & $\mathrm{F}$ & 79 & Não & Sim & Não \\
\hline 17 & Nova Veneza & $\mathrm{F}$ & 80 & Sim & Sim & Não \\
\hline 18 & Forquilhinha & $\mathrm{F}$ & 64 & Não & Sim & Sim \\
\hline 19 & Forquilhinha & $\mathrm{F}$ & 60 & Sim & Sim & Sim \\
\hline 20 & Forquilhinha & $\mathrm{F}$ & 78 & Sim & Sim & Não \\
\hline 21 & Forquilhinha & $\mathrm{F}$ & 72 & Não & Sim & Não \\
\hline 22 & Nova Veneza & $M$ & 69 & Não & Sim & Não \\
\hline 23 & Treviso & $\mathrm{F}$ & 60 & Não & Sim & Não \\
\hline 24 & Treviso & $\mathrm{F}$ & 57 & Não & Sim & Não \\
\hline 25 & Treviso & $\mathrm{F}$ & 69 & Não & Sim & Sim \\
\hline 26 & Treviso & $\mathrm{F}$ & 82 & Sim & Sim & Sim \\
\hline 27 & Treviso & $\mathrm{F}$ & 61 & Não & Sim & Não \\
\hline 28 & Treviso & $\mathrm{F}$ & 72 & Sim & Sim & Não \\
\hline 29 & Treviso & $\mathrm{F}$ & 59 & Não & Sim & Não \\
\hline 30 & Treviso & $\mathrm{F}$ & 67 & Sim & Sim & Sim \\
\hline
\end{tabular}

Fonte: coleta de dados em pesquisa de campo

Conforme demonstra a Tabela 1 foram entrevistados no total 30 idosos, sendo sete homens e 23 mulheres $^{3}$, com idades entre 57 e 82 anos. No que se refere aos municípios, 17 idosos residem em Forquilhinha, cinco em Nova Veneza e oito em Treviso. Em sua maioria, os idosos são casados, com exceção de cinco mulheres viúvas. Todos os entrevistados são aposentados pela PSR, e as mulheres viúvas além de aposentadas também são pensionistas, acumulando assim ambos os benefícios.

Dentre os trinta entrevistados, 25 informaram que adquiriram bens materiais após se aposentarem. A aquisição de produtos varia de acordo com a renda dos idosos. Aqueles que possuem a PSR como fonte única de renda se restringem a adquirir bem mais básicos. Em contrapartida, os idosos que possuem a PSR como renda complementar se permitem maior conforto consumindo em sua maioria produtos que proporcionam maior qualidade de vida.

\footnotetext{
${ }^{3}$ O número maior de mulheres entrevistadas justifica-se pelo critério de acessibilidade adotado na construção da amostra.
} 
No primeiro caso, dos idosos que possuem apenas a renda da PSR, o valor do benefício é destinado principalmente ao pagamento de contas básicas como energia, gás e alimentação, conforme relatam as entrevistadas:

Sempre deu pra se virar, a aposentadoria é para o rancho e medicamento. (ENTREVISTADA $\mathrm{N}^{\circ} 8$ ).

Eu moro sozinha, mas tudo depende de mim, desde o gás, a energia, comida e o que tiver que pagar. (ENTREVISTADA $\mathrm{N}^{\circ} 14$ ).

É a comida, luz, água e remédio, quando chega no fim do mês é só o que tu comprou, não sobra mais nada. Tem vezes que ainda não dá [...] Se não tivesse esse dinheiro não sei o que seria de nós. (ENTREVISTADA N²1).

Esses idosos também relataram que conseguiram melhorar o padrão de vida, através da aquisição de bens básicos como móveis e eletrodomésticos. A entrevistada $n^{\circ} 19$ relata inclusive a divisão no orçamento entre ela e seu marido, ambos aposentados, de modo a conseguirem pagar as contas e comprar o que precisam:

Muita coisa a gente comprou [...] Lá em casa é assim, um mês eu pago a luz e água, outro mês é meu marido. E se nós compramos uma cozinha juntos, então uma prestação é minha e outra dele. E eu gasto bastante com remédio também né! Faltava muita coisa na casa, daí a gente se ajudou. Gastamos a metade cada um assim, onde conseguimos. (ENTREVISTADA N¹9).

Há eu fiz minha cozinha toda nova, ficou linda! (ENTREVISTADA $N^{\circ}$ 30).

Em meio às entrevistas, também foi possível identificar que o empréstimo consignado é um mecanismo ao qual o idoso recorre visando a adquirir bens que não possui condições de comprar à vista, conforme relata a Entrevistada $n^{\circ} 28$ :

É só porque eles veem que a gente tem, recebemos por mês. Eu já fiz empréstimo consignado quando eu fiz a casa. Aí eu queria fazer uma cozinha sob medida e faltava um pouco de dinheiro. Eu não queria ficar pagando prestação, aí eu fui lá na Caixa e fiz um consignado de $\mathrm{R} \$ 80,00$ por mês, e descontou sem perceber. Hoje eu estou lá com meu móvel pronto, já terminei de pagar. Já vem descontado da aposentadoria!

Quando se trata do meio rural, estar aposentado é uma garantia de renda mensal até então desconhecida por muitos produtores rurais, visto que a maioria possui renda semestral ou anual, pois ela varia de acordo com o período da safra. Antes da aposentadoria, o consumo era algo muito restrito, pois o agricultor não possuía uma renda fixa. Entretanto, ao se tornar aposentado, o idoso é convidado a participar do comércio, podendo efetuar suas compras em prestações, e até mesmo realizar empréstimos em instituições financeiras a juros mais baixos, o que não é o caso da maioria dos agricultores.

No que tange ao papel desempenhado pelas instituições na produção de valores morais, inserem-se as contribuições de Douglas (1998). Conforme a 
autora, esses são capazes de estabilizar o fluxo da vida social, criando realidades que se aplicam aos indivíduos. Frente a isso, entende-se que a internalização da PSR exerce um alcance moral na percepção do idoso sobre si mesmo. Denota-se, em meio às falas, que os agricultores se sentem mais seguros em consumir após se aposentarem. Desse modo, evitam o risco de serem julgados pela sociedade, por não conseguirem arcar com os compromissos em casos de eventuais prejuízos das safras.

Ao realizar um estudo na zona rural do nordeste brasileiro, Kato (2006) identificou que as aposentadorias trouxeram melhorias ao meio rural através do aumento monetário da renda familiar. A autora revela que há uma relação direta entre a concessão de aposentadorias e o aumento da qualidade de vida dos domicílios rurais, tendo em vista as melhorias nas condições de moradias e o aumento do acesso aos bens de consumo duráveis por parte dos aposentados.

$\mathrm{Na}$ presente pesquisa, a partir dos relatos dos entrevistados, verifica-se que o mecanismo principal utilizado para adentrar ao comércio é a compra de bens através de prestações. É possível identificar que a garantia de uma renda fixa transmite segurança ao idoso, de modo que ele se sente capaz de assumir mensalmente pequenas parcelas a fim de adquirir aquilo que necessita:

A gente compra umas coisinhas pra dentro de casa, compra à prestação e consegue pagar direitinho. Eu compro à prestação, porque comprar a vista não dá, não está sobrando dinheiro também. Tinha uma época que ninguém tinha uma geladeira dentro de casa porque não dava pra comprar! (ENTREVISTADA №13).

Nós éramos pobres, então depois graças a Deus deu pra comprar as coisinhas que faltava pra dentro de casa, graças a aposentadoria. Eu não tinha quase nada dentro de casa, aí deu pra comprar móveis, eletrodomésticos. A gente tinha só uns trapinhos, e agora já deu pra comprar umas coisas melhores, roupas melhores. (ENTREVISTADA $\left.\mathrm{N}^{\circ} 27\right)$.

A gente faz a prestação conforme vê que dá. Se eu vou fazer uma prestação de $R \$ 120,00$, é só aquilo. Eu só vou comprar outra coisa depois de pagar aquilo. Porque nós não vamos gastar todo nosso aposento em móveis, e daí pra comer? E para o remédio? (ENTREVISTADA N²8).

A fim de entender essa mudança de hábito no que se refere ao consumo, cabe retomar as contribuições de Hodgson (2006). Para o autor, um hábito pode emergir em determinado contexto, a partir de um estímulo, como uma disposição a se engajar em novos comportamentos. Nesse caso, o consumo através de financiamentos e prestações teve como estímulo a PSR. Essa, ao ser internalizada na vida dos idosos, por se traduzir em uma renda mensal, contribuiu para que os idosos desenvolvessem o hábito de comprar em prestações.

O conceito de efeito reconstitutivo descendente proposto por Hodgson (2003) também é central para entender o consumo dos idosos. Segundo o autor, as instituições podem exercer uma pressão persuasiva sobre os indivíduos, capaz de moldar suas aspirações, desejos e preferências. Assim, pode-se inferir que a PSR atuou na reconstituição dos hábitos dos idosos no que se refere ao consumo, pois o que se verificou foi uma mudança de 
comportamento. Afinal, antes da aposentadoria, por falta de recursos, os idosos não tinham o hábito de frequentar o comércio e, quando o faziam, efetuavam suas compras à vista.

Quanto aos idosos que possuem a PSR como renda complementar, em alguns casos, verificou-se que o benefício é destinado ao pagamento das contas fixas. Assim, indiretamente essa renda favorece o consumo, uma vez que o recurso que antes era reservado para as despesas da casa, agora pode ser empregado na aquisição de outros bens, conforme relata o Entrevistado $n^{\circ} 9$ :

\begin{abstract}
Eu comprei um carro zero, e com a minha aposentadoria eu pago o carro. Você tem essa renda que é uma garantia, ela te permite que com o outro dinheiro você compre outras coisas. Aí você sabe que aquele é garantido, e pode usar o outro pra comprar alguma coisa. Então indiretamente ele te permite comprar.
\end{abstract}

No que se refere a esses idosos que possuem a PSR como renda complementar, também se identificou que, embora a maioria tenha desenvolvido o hábito de comprar a prazo, há aqueles que não abrem mão de comprar à vista. Nestes casos, denota-se a sobreposição de um estilo de vida, visto que alguns idosos preferem fazer economia e juntar o valor que necessitam para efetuar determinada compra à vista, conforme relatam as entrevistadas:

\begin{abstract}
Comprei esse freezer e geladeira semana passada, foi com meu dinheiro porque eu vou guardando. Eu não gosto de comprar em prestação, daí quando eu tenho ali bastante eu compro uma peça, compro aquela geladeira, e eu vou trocando. [...] É uma garantia! Eu compro minhas coisinhas, dou presente. Fim de ano me ajuda bastante. (ENTREVISTADA N¹6).
\end{abstract}

A gente comprou bastante! Mas nunca dou o passo maior que a perna né! Eu sempre faço em duas vezes ou à vista, porque eu não gosto de deixar o dinheiro lá, daí é melhor pagar à vista né! (ENTREVISTADA N²3).

As entrevistas também permitiram identificar a internalização da PSR na autonomia da mulher frente ao cônjuge. Percebe-se, em meio às suas falas, que antes da aposentadoria as mulheres eram dependentes de seus maridos, pois eram eles que administravam o recurso proveniente da lavoura. Como o dinheiro era empregado em sua maior parte no pagamento das contas básicas, as mulheres praticamente não tinham acesso à renda e, quando precisavam, tinham que pedir ao marido. Com a aposentadoria, as mulheres passam a ter acesso direto à renda e adquirem com isso maior independência e poder de decisão frente ao cônjuge. Esse, após se aposentar, permanece responsável pelas contas fixas da casa, e a mulher conquista a autonomia de comprar o que quer com sua renda, conforme relatam as entrevistadas:

Eu dependia muito do outro né, agora eu não peço mais nada porque o dinheiro que eu ganho é tudo pra mim. [...] É pouco, mas se saber repartir dá pra fazer bastante. Ele não pertence pra comprar comida pra dentro de casa essas coisas. (ENTREVISTADA ${ }^{\circ}{ }^{16}$ ).

Eu não dependo do meu marido. Eletrodoméstico já comprei muito, eu compro bastante coisa! [...] Não é muito, mas antes isso do que 
nada né. A pessoa que está na roça, com 60 anos, depender ainda do marido, aí é ruim né! [...] Graças a Deus as roupas que eu tenho eu compro tudo com o dinheiro que eu me aposentei. Não dependo mais nada do meu marido. E uma vez, que os maridos não davam nada pra mulher?! (ENTREVISTADA ${ }^{\circ} 23$ ).

Em seu dossiê Previdência Social Rural e gênero, Brumer (2002) ressalta a problemática da invisibilidade do trabalho feminino. Embora as mulheres exerçam inúmeras tarefas destinadas à produção, o fato de suas atividades serem domésticas faz com que elas não sejam reconhecidas como trabalho. Também por esse motivo, antes da aposentadoria, as mulheres eram mais dependentes de seus cônjuges.

No debate sobre gênero, Brumer (2002) ressalta que as mulheres ganham destaque como beneficiárias da PSR por terem acesso ao benefício cinco anos antes que os homens. Segundo a autora, a PSR se traduz em valor simbólico, pois as mulheres que nunca tiveram remuneração pelos trabalhos realizados passam a ter uma conta e um cartão em seus próprios nomes, com uma renda regular. Com isso, elas adquirem maior consciência sobre seus direitos, bem como a autonomia para decidirem como irão utilizar o recurso.

A presente pesquisa também permitiu identificar que, após a aposentadoria, os idosos passam a dedicar mais tempo e renda às atividades relacionadas ao entretenimento. Visto que a maior parte das entrevistas foi realizada em Clubes da Terceira Idade e Clube de Mães, a partir delas, identificou-se que, ao se aposentarem, muitos idosos passam a interagir nas confraternizações desses grupos. Em meio à interação social, os idosos passam a despender parte da renda com novas atividades, a exemplo de passeios, confraternizações e viagens em grupo, conforme relatam as entrevistadas:

\footnotetext{
Se não é a terceira idade onde que nós íamos conhecer tantos lugarzinhos! (ENTREVISTADA Nº10).

O ano passado eu fui para Aparecida, aí agora estou pagando de novo. É bastante amiga, tudo gente conhecida, e a gente se sente bem né! (ENTREVISTADA N²5).

É, eu não tenho dinheiro em poupança, eu vou lá recebo, e já tenho onde botar. E eu passeio, já fui pros EUA, e agora estou com vontade de ir o ano que vem pra Europa com a nora e o filho passear, então a gente tem que ir guardando né, da aposentadoria. (ENTREVISTADA $\left.\mathrm{N}^{\circ} 28\right)$.
}

De acordo com Bourdieu (2005) o gosto, sendo a fórmula geradora que se encontra na origem do estilo de vida, é capaz de assemelhar coisas e pessoas que se ligam. Para esse autor, as decisões, em sua maior parte, ocorrem em meio a um coletivo, o que permite inferir que a interação social levou os idosos a aderirem a tais entretenimentos.

Ademais, cabe salientar segundo Douglas (1998) que o pensamento institucional em meio a um grupo legitimado pode condicionar a ação humana, levando os indivíduos a desenvolverem preferências e sentimentos semelhantes, sustentando desta forma o padrão de interação. Por este motivo, 
a autora revela que o agrupamento social é definido pelo seu estilo de pensamento.

Nesta pesquisa, para além da internalização no consumo, no entretenimento e na autonomia da mulher, verificou-se que, na maioria dos casos, a PSR tem como destino a aquisição de medicamentos. Conforme relataram alguns entrevistados, o Sistema Único de Saúde (SUS) não fornece todos os remédios necessários, então nesses casos os idosos recorrem à aposentadoria. Essa renda também é direcionada à saúde quando os idosos precisam realizar consultas médicas. A maior parte dos entrevistados não possui plano de saúde, então quando emerge a necessidade de uma consulta médica é preciso pagar pelo acesso ao serviço privado:

$\mathrm{Ai}$ eu acho que um aposento vai só pra remédio. Imagina cada injeçãozinha que eu faço no meu joelho é $R \$ 80,00$. Se é pra eu depender de eu trabalhar pra mim viver, eu morro de fome. (ENTREVISTADA N¹1).

Gasto muito em remédio, muito mesmo. É difícil, porque os remédio mais caro no SUS não tem, e as vezes também nem aquele mais simples também não tem. E como eu preciso urgente, eu sou obrigada a comprar na farmácia. (ENTREVISTADA N¹7).

Os remédios que a gente precisa, o posto não é tudo que dá, as vezes a gente tem que comprar. Por exemplo, uma consulta as vezes tem que pagar, então aquele dinheiro ali ajuda. (ENTREVISTADA $\left.\mathrm{N}^{\circ} 23\right)$.

Conforme a Tabela 1, dentre os trinta entrevistados, apenas quatro declaram que não adquiriram bens materiais após se aposentarem. Todavia, eles relataram que ajudam financeiramente filhos e netos. Conforme mostra a tabela, 12 idosos exercem essa contribuição. Em alguns casos, o auxílio não é feito necessariamente em dinheiro, mas em alimentos, sendo essa a melhor forma que o agricultor encontra para ajudar seus familiares. A seguir estão alguns depoimentos em que os idosos relatam tais situações:

Olha, sabes que sempre tem aquele que é solidário. [...] Tem pessoas que conseguem chegar a esse ponto de se aposentar e continuar ainda produzindo na sua atividade. Aquilo ali passa a ser mais uma renda, então ele até pode ajudar um filho, ou ajudar uma outra pessoa. (PRESIDENTE DO SINDICATO DOS TRABALHADORES RURAIS DE IÇARA).

Meus filhos, estou ajudando ainda, eles têm uns financiamentos e eu estou ajudando. (ENTREVISTADA N¹0).

Que nem os meus filhos, nós moramos ali, e eles dependem de nós ainda, porque uma carne eles não compram, ovos eles não compram. Eles só fazem aquele ranchinho, e vêm pegar tudo lá em casa. (ENTREVISTADA N²3).

Eles trabalham, mas comem ali em casa, porque a gente é uma família né, trabalha junto. A gente ajuda os filhos, porque os filhos comem em casa né. Eles trabalham, mas sabe como é, eles não ganham lá muito dinheiro [...] Eu também tenho as netas, que é 
sempre assim, então a gente ajuda um pouco. (ENTREVISTADA $\left.\mathrm{N}^{\circ} 25\right)$.

Percebe-se, a partir dos depoimentos, que em alguns casos o auxílio dos idosos é destinado àqueles filhos que permanecem com dificuldade no meio rural. Em outras falas, a contribuição dos idosos é com os filhos que trabalham fora do meio rural, mas que também enfrentam dificuldades e, por isso, se alimentam na casa dos pais. Essa situação é marcada pelo habitus, característico do camponês, de fazer as refeições em família. "Onde come um, comem dois!" - Este pensamento está atrelado ao estilo de vida de quem vive no campo. Frente a isso, ajudar os filhos, fornecendo-lhes alimentos, torna-se uma prática comum no meio rural.

Nesses casos, verifica-se novamente a relação da PSR com a formação dos valores morais, visto que o benefício inverte o papel do idoso dentro do ambiente familiar, de modo que ele passa a dar assistência frente às necessidades da família. Em contrapartida, antes da implementação da PSR, ao abandonarem a atividade agrícola por motivos de doença, os idosos se tornavam dependentes de seus filhos. Por esse motivo, fala-se que a PSR inverteu o papel do idoso no ambiente familiar. Para Delgado e Cardoso Jr. (1999) essa inversão de papéis garante a valorização e a autonomia do idoso no contexto em que ele está inserido. Alguns idosos falaram sobre o sofrimento dos seus pais à época em que não havia a PSR, e reconhecem que essa renda trouxe-lhes independência:

A gente gasta muito com remédio, mas e se não fosse isso aí? Que nem os nossos pais que não tinham nada! Eles quando conseguiram ganhar um pouquinho já logo faleceram. (ENTREVISTADA Nº).

Agora a gente fica independente, entra o dinheirinho lá. Se não pode trabalhar vai depender dos filhos? Aí dinheiro de onde se não pode trabalhar? (ENTREVISTADO Nº).

Se a gente tem o troquinho da gente, já é muita coisa. [...] Eu me lembro da minha falecida mãe, das minhas tias: elas viviam na roça, velhinhas, sem um trocadinho, não dava nem pra comprar uma roupinha. (ENTREVISTADA N²3).

Se não fosse aposentada eu estaria à custa dos filhos, só o que me falta. É sobrevivência! (ENTREVISTADA N³0).

O Presidente do Sindicato dos Trabalhadores Rurais de Içara revela a importância da PSR para manutenção do idoso do campo, bem como a transformação proporcionada pela renda na vida dos idosos e de seus familiares:

O pessoal lá na agricultura, ainda ele consegue aos trancos e barrancos chegar até os 60 anos e aí ele permanecer (que é o direito do homem se aposentar e a mulher é 55). Depois que ele consegue receber esse benefício a gente vê a transformação da família. [...] Passou a ter um dinheirinho para pelo menos comprar o remédio, para alimentação, então ele passou a ter outra qualidade de vida [...] $\mathrm{Na}$ atividade da agricultura eles têm a dificuldade, porque a renda que entra não é mensal. São poucos aqueles que têm a renda mensal, às vezes ela é semestral, ou até anual. Então aqueles que têm o benefício da previdência, eles usam isso para o sustento da família, 
diário e mensal: é energia, sempre tem que comprar alguma coisa no mercado, é o remédio, é a consulta onde eles acabam fazendo uso desse dinheiro.

Em um estudo realizado com 65 idosos rurais, no município de Viçosa/MG, Tavares et al (2011) demonstram que $80 \%$ dos aposentados eram responsáveis por, no mínimo, metade da renda de suas famílias. Deste modo, embora a renda da aposentadoria seja considerada uma ajuda, ela é imprescindível para a sobrevivência das famílias rurais, o que denota, em muitos casos, situação de dependência. Dentre os motivos que levam à situação de dependência Tavares et al (2011) destacam os problemas econômicos e familiares, desemprego e baixa remuneração, independente de os filhos coabitarem ou não com os idosos. Ademais, estes autores revelam que na percepção dos idosos, contribuir para a manutenção econômica de suas famílias é uma obrigação.

Após concluir a análise acerca do consumo e autonomia dos idosos, a seguir estão as considerações finais acerca do que foi observado no decorrer desta pesquisa.

\section{Considerações finais}

De modo geral, essa análise permitiu identificar que a PSR se naturaliza na vida dos idosos ultrapassando seu estágio de convenção frágil, instituindo-se em meio ao habitus e internalizando-se através da reconstituição dos hábitos. Em suma, verificou-se que a PSR ganha destaque por se tornar uma renda indispensável à vida dos idosos através de três eixos centrais.

No que tange ao consumo, a PSR fixa identidade por meio da reconstituição do hábito, possibilitando a aquisição de produtos através de prestações e financiamentos. Constatou-se a questão do efeito reconstitutivo descendente, na qual a PSR passou a moldar as disposições, preferências, metas, capacidades, habilidades e até mesmo os valores individuais dos idosos.

O segundo importante meio pelo qual a PSR internaliza-se é na autonomia da mulher frente ao cônjuge; por se constituir em uma fonte de renda fixa, a PSR se traduz em poder de compra e por consequência adquire um valor simbólico, visto que a mulher passa a ter mais poder de decisão e maior consciência sobre seus direitos. E por fim, verificou-se a relação da PSR com a formação dos valores morais, visto que o benefício inverte o papel do idoso dentro do ambiente familiar, de modo que ele passa a dar assistência frente às necessidades da família.

Na perspectiva dos idosos, a PSR possui um significado singular. Para alguns, ela representa um complemento na renda, permitindo mudanças e melhorias no padrão de vida. Para outros, ela é a única fonte de renda responsável pela manutenção da sobrevivência, principalmente no que se refere à saúde e alimentação. De modo geral, em ambos os casos, verifica-se que a PSR exerce um papel fundamental na vida dos idosos, pois todos concordam que sem essa renda seria muito mais difícil encarar 0 envelhecimento.

Por fim, a PSR internaliza-se ao se tornar, de política pública, um meio pelo qual os idosos conseguem viver melhor essa fase da vida. Tal renda possibilita a inserção dos idosos em atividades sociais e culturais, de modo 
que, em meio à vivência, eles partilham suas experiências de vida. A PSR se internaliza, portanto, ao garantir autonomia e independência, criando assim as condições para que a velhice seja um momento propício à elaboração e execução de projetos de vida.

\section{REFERÊNCIAS}

ASSOCIAÇÃO DOS MUNICÍPIOS DA REGIÃO CARBONÍFERA. Santa Catarina: 2013. Disponível em <http://www.amrec.com.br/home/>. Acesso em 22 fev. 2014.

BARROS, Myriam Moraes Lins de. TRAJETÓRIA DOS ESTUDOS DE VELHICE NO BRASIL. Sociologia, Problemas E Práticas, n. 52, p.109-132, 2006.

BEZERRA, Antonio Jorge Amaral. A agricultura familiar e a universalização dos direitos sociais: estudo sobre a previdência social rural no município de Morro Redondo, Rio Grande do Sul. 2006. Tese. (Doutorado em Agronomia) Curso de Pós-Graduação em Agronomia, Universidade Federal de Pelotas, Pelotas - $\quad$ RS. Disponível em: http://capesdw.capes.gov.br/capesdw/resumo.html?idtese $=2006294200301601$ 0p7. Acesso em 21 fev. 2012.

BOURDIEU, Pierre. O campo econômico. Política e Sociedade, v. 4, n. 6, p.15-57, 2005.

A distinção: crítica social do julgamento. São Paulo e Porto Alegre: Edusp e Zouk, 2008. 556 p.

BRUMER, Anita. Previdência social rural e gênero. Sociologias, Porto Alegre, v 4, n. 7, p.50-81, jan/jun 2002.

CALDAS, Nádia Velleda. Agricultura familiar e previdência social rural: um estudo comparativo em quatro municípios gaúchos. 2008. Dissertação. (Mestrado em Sistemas de Produção Agrícola Familiar) - Curso de PósGraduação em Sistemas de Produção Agrícola Familiar, Universidade Federal de Pelotas, Pelotas - RS. Disponível em: http://capesdw.capes.gov.br/capesdw/resumo.html?idtese $=2008942003016025$ p4. Acesso em 22 fev. 2012.

DELGADO, Guilherme C.; CARDOSO Jr., José Celso. $\mathbf{0}$ idoso e a previdência rural no Brasil: a experiência recente de universalização. Texto para discussão n 688. Brasília: IPEA, 1999.

DOUGLAS, Mary. Como as instituições pensam. São Paulo: EDUSP, 1998. $141 \mathrm{p}$.

DRAIBE, Sonia. Rumos e metamorfoses: um estudo sobre a Constituição do Estado e as alternativas da industrialização no Brasil, 1930-1960. São Paulo: Paz e Terra, 1985. 399 p. 
GIL, Antônio Carlos. Métodos e técnicas de pesquisa social. São Paulo: Atlas, 1999. 206 p.

HODGSON, Geoffrey. The hidden persuaders: institutions and individuals in economic theory. Cambridge Journal of Economics, v. 27, pp. 159-175, 2003.

n.1, pp. 1-25, 2006.

What are institutions? Journal of Economic Issues, v. 40,

IBGE. Banco de Dados Agregados. Censo 2010. Disponível em http://www.sidra.ibge.gov.br/bda/tabela/listabl.asp?c=1552\&z=cd\&o=5. Acesso em: 10 fev. 2012.

IPEA. Estado e uma nação. Políticas Sociais: acompanhamento e análise, $n$ 18. Brasília: IPEA, 2010.

Ministério da Previdência Social. Estatísticas municipais 2013. Disponível em: <http://www.mpas.gov.br/conteudoDinamico.php?id=483>. Acesso em: 20 abr. 2013.

KATO, Rosa. Previdência social na zona rural do Nordeste brasileiro: análise do seu impacto sobre a pobreza e a distribuição de renda em 1991 e 2000. 2006. 91 pg. Dissertação (Mestrado) - Curso de Economia, Economia, Universidade Federal da Paraíba, João Pessoa, 2006.

MOTTA, Alda Britto da. A atualidade do conceito de gerações na pesquisa sobre o envelhecimento. Sociedade e Estado, vol.25, n.2, p. 225-250, 2010.

PITELIS, Christos. "On the nature of the capitalist state." Review of political economy, 6(1): 72-105, 1994.

SCHWARZER, Helmut; QUERINO, Ana Carolina. Benefícios sociais e pobreza: programas não contributivos da seguridade social brasileira. Texto para discussão nº 929. Brasília: IPEA, 2002.

SCREPANTI, Ernesto. The Fundamental Institutions of Capitalism. Londres: Routledge, 2001.

SKOCPOL, Theda. Bringing the State Back In. Cambridge: Cambridge University Press, 1985.

SUGAMOSTO, Marisa. Velhice e benefício previdenciário entre os agricultores familiares do município de Colombo - Paraná. In. (Orgs.) BRANDENBURG, Alfio et al. Ruralidades e Questões ambientais: estudo dobre estratégias, projetos e políticas. Brasília: MDA, 2007.

TAVARES, Vivian Oliveira; TEIXEIRA, Karla Damiano; WAJNMAN, Simone; LORET, Maria das Dores Saraiva de. Interfaces entre a renda dos idosos aposentados rurais e o contexto familiar. Textos e Contextos, Porto Alegre, v.10, n. 1, p.94-108. jan-jul. 2011. 